\title{
Kelimpahan Relatif dan Preferensi Habitat pada Kepiting Mangrove (Uca spp.) di Kabonga Kecil, Donggala, Sulawesi Tengah
}

\section{Relative Abundance and Habitat Preferences on Mangrove Crab (Uca spp.) in Kabonga Kecil, Donggala, Central Sulawesi}

\author{
Donny Aprilyanto*), Fahri dan Annawaty \\ Jurusan Biologi, Fakultas MIPA, Universitas Tadulako \\ Jl. Soekarno-Hatta. Km 9, Tondo, Palu 94118, Sulawesi Tengah, Indonesia.
}

\begin{abstract}
The objective of this study was to determine the relative abundance and habitat preferences of mangrove crab which belong to Family Ocypodidae (Uca spp.) in habiting intertidal area of mangrove forest in Kabonga Kecil, Donggala, Central Sulawesi. Sample was colletion in January 2017 using purposive sampling method at 4 stations. The results showed there are 6 species of crabs of genus $U c a$ in Kabonga Kecil namely Uca annulipes, $U$. triangularis, $U$. perplexa, $U$. dussumieri, $U$. demani, and $U$. vocans distributed on 3 types of habitat i.e. muddy substrate, sandy substrate and muddy sand substrate.The abundance of each species are $U$. dussumieri $75 \%$; U. demani 100\%; U. demani 68.67\%; and 4: $\mathrm{U}$. dussumieri $67.65 \%$ respectively from station 1 to 4 . The mangrove forest temperatures in Kabonga Kecil, ranging from $26^{\circ} \mathrm{C}-30^{\circ} \mathrm{C}$ while $\mathrm{pH}$ ranges from $5 \%-6.1 \%$.
\end{abstract}

Keywords: Crab, Uca, Mangrove forest, Sulawesi.

\begin{abstract}
ABSTRAK
Penelitian ini bertujuan untuk mengetahui kelimpahan relatif dan preferensi habitat kepiting mangrove Famili Ocypodidae (Uca spp.)di zona intertidal di Kabonga Kecil, Donggala, Sulawesi Tengah. Koleksi sampel dilaksanakan pada bulan Januari 2017 menggunakan metode purposive sampling pada 4 stasiun. Hasil penelitian menunjukkan terdapat 6 spesies kepiting genus $U c a$ di Kabonga Kecil yaitu Uca annulipes, U. triangularis, $U$. perplexa, U. dussumieri, $U$. demani, dan $U$. vocans yang tersebar pada 3 tipe habitat yaitu substrat berlumpur, substrat berpasir dan substrat pasirberlumpur.Kelimpahan dari masingmasing spesies adalah U. dussumieri 75\%; U. demani100\%; U. demani 68,67\%; dan 4: $U$. dussumieri $67,65 \%$ berturut-turut dari stasiun 1 sampai 4 . Hutan mangrove di Kabonga Kecil memiliki suhu substrat yang berkisar antara $26^{\circ} \mathrm{C}-30^{\circ} \mathrm{C}$ sedangkan $\mathrm{pH}$ berkisar antara $5,0 \%$ $-6,1 \%$.
\end{abstract}

Kata kunci: Kepiting,Uca, Hutan mangrove, Sulawesi. 


\section{LATAR BELAKANG}

Kepiting genus $U c a$ merupakan jenis kepiting dari kelompok Ordo Decapoda dan termasuk ke dalam Famili Ocypodidae, yaitu salah satu kelompok kepiting penghuni tetap daerah pasang surut ekosistem mangrove, beberapa spesies dari kepiting ini ditemukan dalam jumlah yang melimpah. Kepiting ini merupakan kelompok kepiting yang hidup dengan membuat liang sebagai tempat tinggal,selain itu liang liang juga berfungsi sebagai tempat perlindungan diri terhadap temperatur yang tinggi ketika air laut pasang, karena air yang berada dalam lubang galian dapat membantu pengaturan suhu tubuh melalui evaporasi (Smith \& Miller, 1973; Crane, 1975).

Kepiting Uca memiliki peranan penting pada rantai makanan yang berlangsung dalam ekosistem mangrove, karena berperan sebagai pemakan detritus (Pratiwi, 2010a). Menurut Rosenberg (2001), kepiting $U c a$ adalah jenis kepiting dengan ukuran tubuh yang kecil serta memiliki dimorfisme sexual yang terlihat pada capit jantan dan betina. Pada salah satu capit kepiting Uca jantan memiliki ukuran yang lebih besar dibandingkan dengan capit lainnya, berbeda dengan kepiting Uca betina yang kedua capitnya berukuran kecil. Capit besar pada kepiting Uca jantan berfungsi sebagai alat yang digunakan untuk melindungi diri dari musuh atau serangan sesama kepiting jantan dan sebagai alat untuk menarik perhatian kepiting betina. Capit kecil berfungsi sebagai alat makan (Murniati \& Pratiwi, 2015).

Salah satu wilayah hutan mangrove yang ada di daerah Sulawesi Tengah yaitu hutan mangrove yang terdapat di Kabonga Kecil, Donggala, Sulawesi Tengah. Penelitian ini bertujuan untuk melaporkan kelimpahan relatif dan preferensi habitat dari kepiting Uca yang terdapat di hutan mangrove pada wilayah tersebut.

\section{BAHAN DAN METODE}

Penelitian ini dilaksanakan di hutan Mangrove Kelurahan Kabonga Kecil pada bulan Januari 2017. Pemilihan stasiun pengamatan pada wilayah hutan mangrove dilakukan secara sengaja atau purposive dengan pertimbangan bahwa stasiun pengoleksian merupakan habitat dari kepiting Uca. Stasiun penelitian ditentukan berdasarkan hasil survei pendahuluan yang dilakukan pada bulan Juni 2016 yang berjumlah 4 stasiun pengoleksian kepiting Uca.

Koleksi dilakukan secara langsung di empat stasiun yang merupakan wilayah hutan mangrove pada daerah zona intertidal saat air laut surut. Titik pengambilan sampel ditentukan secara purposive (penentuan titik sampel berdasarkan habitat). Koleksi kepiting dilakukan dengan 
menggunakan sekop kecil untuk menggali liang kepiting atau dengan tangan kosong (hand capture), kemudian faktor fisika dan kimia lingkungan seperti suhu liang kepiting diukur dengan thermometer, serta $\mathrm{pH}$ tanah diukur dengan Soil Taster. Sampel kepiting hasil tangkapan kemudian dilemaskan menggunakan air yang ditambahkan es batu. Setelah itu dilanjutkan dengan proses preservasi sampel dengan menggunakan alkohol $40 \%$ (Daisy Wowor komunikasi pribadi 2016) dan selanjutnya diberi label. Seluruh kepiting Uca yang telah dipreservasi kemudian diidentifikasi jenisnya menggunakan Murniati \& Pratiwi (2015) dan Crane (1975), kemudian dihitung jumlah individu yang diperoleh.

\section{Analisis Data}

Data yang diperoleh dianalisis secara deskritif mengenai habitat kepiting Uca sedangkan kelimpahan relatif kepiting Uca ditentukan dengan menggunakan rumus Krebs (1972):

$$
\mathrm{Kr}=\frac{n i}{\mathrm{~N}} \times 100 \%
$$

Dimana :

$\mathrm{Kr}=$ Kelimpahan Relatif

$\mathrm{Ni}=$ Jumlah Individu Spesies ke-i

$\mathrm{N}=$ Jumlah Total Individu Semua Spesies

\section{HASIL DAN PEMBAHASAN}

Berdasarkan hasil penelitian yang dilakukan di empat stasiun sampling ditemukan 6 spesies kepiting genus Uca (Tabel 1).

\section{Populasi}

Berdasarkan hasil yang diperoleh jumlah populasi terbanyak dari keenam spesies kepiting Uca didapatkan pada spesies $U$. dussumieri sebanyak 141 individu dan $U$. demani sebanyak 130 individu (ST1 dan ST2) serta jumlah populasi yang terendah pada spesies $U$. vocans sebanyak 1 dan 2 individu (ST1 dan ST4). Kepiting spesies U. demani hadir diseluruh stasiun pengamatan (Tabel 1). Hal ini menunjukan bahwa $U$. demani dapat beradaptasi dengan baik pada semua tipe habitat. Hal ini disebabkan oleh kemampuan kepiting Uca untuk dapat beradaptasi secara baik terhadap kondisi lingkungan yang sangat luas yang ada di hutan mangrove kabonga kecil. Beberapa spesies Uca juga dapat hidup bersama dengan $U$. demani di lokasi hutan mangrove yang sama tetapi spesies $U c a$ tersebut memiliki preferensi habitat yang juga berbeda, sehingga relung ekologi dari kepiting ini dapat saja terpisah. 
Tabel 1. Populasi spesies kepiting genus $U c a$ di hutan mangrove Kabonga Kecil, Donggala, Suawesi Tengah

\begin{tabular}{llcccccc}
\hline \multirow{2}{*}{ No } & Spesies & \multicolumn{5}{c}{ Populasi } \\
\cline { 3 - 7 } & & ST1 & ST2 & ST3 & ST4 & Jmlh \\
\hline 1. & Uca (Tubuca) dussumieri (Milne-Edwards, 1837) & 141 & 0 & 0 & 69 & 210 \\
2. & Uca (Paraleptuca) perplexa (Milne-Edwards, 1837) & 15 & 0 & 12 & 17 & 44 \\
3. & Uca (Paraleptuca) triangularis (Milne-Edwards, 1837) & 20 & 0 & 0 & 0 & 20 \\
4. & Uca (Gelasimus) vocans (Linnaeus, 1758) & 1 & 0 & 4 & 2 & 7 \\
5. & Uca (Paraleptuca) annulipes (Milne-Edwards, 1837) & 5 & 0 & 10 & 0 & 15 \\
6. & Uca (Tubuca) demani (Ortmann, 1897) & 6 & 130 & 57 & 14 & 207 \\
\hline & Jumlah & 188 & 130 & 83 & 102 & 501 \\
\hline
\end{tabular}

\section{Preferensi Habitat}

Enam spesies kepiting $U c a$ yang dikoleksi dari wilayah hutan mangrove di Kelurahan Kabonga Kecil menempati 3 tipe habitat yaitu hutan mangrove dengan substrat berlumpur, substrat pasir berlumpur dan substrat berpasir (tabel 2).

Dari keenam spesies kepiting $U c a$, 2 spesies ditemukan di 1 tipe habitat dan 4 spesies cenderung ditemukan di 2 tipe habitat. Spesies $U c a$ yang ditemukan hanya pada 1 tipe habitat yaitu $U$. dussumier dan $U$. triangularis. U. dussumieri menempati tipe habitat hutan mangrove dengan substrat berlumpur, dimana beberapa liang dari spesies ini berada disekitar akar tumbuhan bakau serta ada pula liang yang tidak memiliki tutupan vegetasinya di sekitarnya..

\section{Uca triangularis memiliki} persamaan dengan $U$. dussumieri yaitu hanya ditemukan di 1 tipe habitat saja. Tipe habitat $U$. dussumieri adalah substrat berlumpur maka tipe habitat dari $U$. triangularis adalah substrat pasir berlumpur dengan keadaan di sekitar liang yang tidak ditumbuhi bakau atau tanpa tutupan vegetasi.

Spesies U. perplexa, U. vocans, $U$. annulipes dan $U$. demani merupakan kepiting Uca yang cenderung ditemukan pada 2 tipe habitat. $U$. perplexa membuat liang pada daerah mangrove dengan tipe habitat berpasir dan pasir berlumpur dimana spesies ini memiliki kesamaan tipe habitat dengan $U$. vocans. Kedua spesies ini sebagian besar membuat liang pada daerah terbuka namun ada juga yang ditemukan dekat dengan akar bakau dan pohon yang tumbang. Spesies $U$. demani dan $U$. annulipes memiliki persamaan tipe habitat yaitu berpasir dan berlumpur dimana beberapa dari kelompok ini hidup dengan membuat liang di sekitar akar tanaman bakau namun ada juga yang hidup dengan membuat liang pada daerah terbuka tanpa tutupan vegetasi. 
Menurut Ravichandran et al. (2001) dan Steenis (1958) faktor yang menyebabkan adanya preferensi habitat, sehingga spesies tertentu dapat ditemukan di satu lokasi namun tidak dijumpai di lokasi lain ialah substrat, salinitas, kemampuan bertahan terhadap arus dan ombak, faktor ketersediaan sumber makanan, serta faktor perlindungan diri dari keadaan disekitar.

\section{Kelimpahan Relatif}

Kelimpahan relatif dari keenam spesies kepiting Uca yang dikoleksi dari wilayah hutan mangrove di Kelurahan Kabonga Kecil dihitung berdasarkan rumus kelimpahan relatif oleh Krebs (1972).

Hasil perhitungan kelimpahan relatif ( Tabel 3) untuk stasiun 1 kelimpahan relatif tertinggi dengan nilai $75 \%$ yaitu $U$. dussumieri, stasiun 2 kelimpahan relatif dengan nilai $100 \%$ yaitu $U$. demani, stasiun 3 kelimpahan relatif tertinggi dengan nilai $68,67 \%$ yaitu $U$. demani, dan stasiun 4 kelimpahan relatif tertinggi dengan nilai $67,65 \%$ yaitu $U$. dussumieri.

Tabel 2. Habitat spesies kepiting genus Uca di hutan mangrove Kabonga Kecil, Donggala, Suawesi Tengah

\begin{tabular}{llc}
\hline No & \multicolumn{1}{c}{ Jenis } & Habitat \\
\hline 1. & Uca (Tubuca) dussumieri (Milne-Edwards, 1837) & Berlumpur \\
2. & Uca (Paraleptuca) perplexa (Milne-Edwards, 1837) & Berpasir dan Pasir berlumpur \\
3. & Uca (Paraleptuca) triangularis (Milne-Edwards, 1837) & Pasir berlumpur \\
4. & Uca (Gelasimus) vocans (Linnaeus, 1758) & Berpasir dan Pasir berlumpur \\
5. & Uca (Paraleptuca) annulipes (Milne-Edwards, 1837) & Berpasir dan Berlumpur \\
6. & Uca (Tubuca) demani (Ortmann, 1897) & Berpasir dan Berlumpur
\end{tabular}

Secara keseluruhan dari keenam spesies yang memiliki kelimpahan relatif tertinggi dan mendominasi disetiap stasiun yaitu $U$. demani dan $U$. dussumieri dibandingkan dengan keempat spesies yang lain. Kelimpahan relatif terendah diantara keenam spesies yang diperoleh yaitu $U c a$ vocans.

\section{Faktor Fisika dan Kimia Lingkungan}

Jika dilihat dari hasil penelitian, suhu untuk stasiun 1, 2, 3 dan 4 cukup bervariasi berkisar antara $27^{\circ} \mathrm{C}-32^{\circ} \mathrm{C}$
(Tabel 4). Beberapa jenis kepiting memiliki toleransi suhu berkisar $26-30^{\circ} \mathrm{C}$. Hal ini berarti suhu pada keempat stasiun masih berada pada batas toleransi bagi pertumbuhan dan perkembangan kepiting Uca (Pratiwi dan Widyastuti, 2013), walaupun ada beberapa stasiun yang memiliki suhu lebih dari $30^{\circ} \mathrm{C}$.

Selain suhu, $\mathrm{pH}$ merupakan salah satu indikator yang mempengaruhi keberadaan kelompok kepiting Uca di suatu wilayah hutan mangrove. Dari hasil 
penelitian $\mathrm{pH}$ pada stasiun $1,2,3$, dan 4 berkisar antara $5 \%-6,1 \%$. Menurut Pratiwi (2010b), pH dengan kisaran tersebut tergolong normal, jika $\mathrm{pH}$ berada pada kisaran yang kurang dari 5 atau lebih dari 9 akan menciptakan kondisi yang tidak menguntungkan bagi kehidupan kelompok Crustaceae. Hal ini berarti stasiun penelitian berada pada $\mathrm{pH}$ yang baik untuk kehidupan kepiting $U c a$.

Tabel 3. Kelimpahan relatif spesies kepiting genus Uca pada setiap stasiun di hutan mangrove Kabonga Kecil, Donggala, Suawesi Tengah

\begin{tabular}{llrrrr}
\hline \multirow{2}{*}{ No } & \multicolumn{1}{c}{ Spesies } & \multicolumn{3}{c}{ Kelimpahan Relatif \% } \\
\cline { 3 - 6 } & & ST1 & ST2 & ST3 & ST4 \\
\hline 1. & Uca (Tubuca) demani (Ortmann, 1897) & 3.19 & 100 & 68.67 & 13.73 \\
2. & Uca (Tubuca) dussumieri (Milne-Edwards, 1837) & 75 & 0 & 0 & 67.65 \\
3. & Uca (Paraleptuca) perplexa (Milne-Edwards, 1837) & 7.98 & 0 & 14.46 & 16.67 \\
4. & Uca (Gelasimus) vocans (Linnaeus, 1758) & 0.53 & 0 & 4.82 & 1.96 \\
5. & Uca (Paraleptuca) annulipes (Milne-Edwards, 1837) & 2.66 & 0 & 12.05 & 0 \\
6. & Uca (Paraleptuca) triangularis (Milne-Edwards, 1837) & 10.64 & 0 & 0 & 0 \\
\hline
\end{tabular}

Tabel 4. Data lingkungan hutan mangrove Kabonga Kecil, Donggala, Suawesi Tengah

\begin{tabular}{llcc}
\hline & Stasiun & Suhu & $\mathrm{pH}$ \\
\cline { 3 - 4 } No & & ${ }^{\circ} \mathrm{C}$ & $6,1 \%$ \\
\hline 1. & Stasiun 1 & $29^{\circ} \mathrm{C}-30^{\circ} \mathrm{C}$ & $5,9 \%-6,1 \%$ \\
2. & Stasiun 2 & $30^{\circ} \mathrm{C}-31^{\circ} \mathrm{C}$ & $5,8 \%-6 \%$ \\
3. & Stasiun 3 & $27^{\circ} \mathrm{C}-30^{\circ} \mathrm{C}$ & $5 \%-5,9 \%$ \\
4. & Stasiun 4 & $29^{\circ} \mathrm{C}-32^{\circ} \mathrm{C}$ & 5 \\
\hline
\end{tabular}

\section{UCAPAN TERIMA KASIH}

Ucapan terimakasih penulis sampaikan kepada Dr. Ir. Daisy Wowor M.Sc dan Dewi Citra Murniati S,Si M,Si yang telah memberikan bimbingan kepada D.A selama melakukan kegiatan magang di Museum Zoologi LIPI. Penulis juga mengucapakan terimakasih kepada seluruh Tim Crustacea yang telah membantu selama proses pengambilan sampel di lapangan.

\section{DAFTAR PUSTAKA}

Crane, J., 1975, Fiddler crabs of the world, Ocypodidae: Genus Uca, Princeton, University Press.

Krebs, C. J., 1978, Ecology, The experimental analisys of distribution and abudance, second edition, Harper and row publisher, New York.

Murniati, D. C., dan Pratiwi, R., 2015, Kepiting Uca di hutan mangrove Indonesia, LIPI Press, Jakarta.

Pratiwi, R., 2010a, Biologi dan ekologi Uca spp. (Crustacea: Decapoda: Ocypodidae) di daerah mangrove di 
Delta Mahakam, Kalimantan Timur, Neptunus, Vol 6 (1), 50-59.

Pratiwi, R., 2010b, Asosiasi Krustasea di Ekosistem Padang Lamun Perairan Teluk Lampung, Ilmu Kelautan, Vol 15 (2), 66-76.

Pratiwi, R., dan Widyastuti, E., 2013, Pola sebaran dan zonasi krustasea di hutan bakau perairan Teluk Lampung, Zoo Indonesia, Vol 22 (1), 11-21.

Ravichandran, S., Soundarapandian, P., dan Kannupandi, T., 2001, Zonation anddistribution of crabs in Pichavaram mangrove swamp, southeast coast of India, Indian Journal Fish, Vol 48 (2), 221-226.

Rosenberg, M.S. 2001. Fiddler crabs claw shape variation: a geometric morphometricanalysis across the genus Uca (Crustacea:Brachyura: Ocypodidae), Biological Journal of the Linnean Society, Vol 75,147162.

Smith, W.K., Miller, P.C. 1973. The thermal ecology of two South Florida fiddler crabs: Uca rapax Smith and Uca pugillator. Bosc. Physiol. Zool. Vol 46, 186-207.

Steenis, C. G. G. J. van., 1958, Ecology of mangroves. In: Flora Malesiana, Noordhoff-Kollf, Djakarta. 